\title{
Indian Bureaucrats across Different Lengths of Service: A Comparative Study
}

\author{
Rashmi Saroha ${ }^{1}$, Prof. N. K. Chadha ${ }^{2}$
}

\section{ABSTRACT}

Occupational stress has been attracting the attention of the researchers since very long now. Decline in performance and productivity as well as an undesirable shift in the work attitude of the employees are just few of its undesirable outcomes. Bureaucracy in India comprises of a fleet of government officials who are employed at both Central and State level. The purpose of the present study was to empirically investigate occupational stress in Indian Bureaucracy and to compare the same on the basis of length of service. Job satisfaction, Resilience and Emotional Intelligence of Indian bureaucrats were also analyzed and compared on the said basis. A sample of 120 civil servants was taken for this study. Four different psychometric scales were used to measure the four variables. Occupational stress levels, Emotional Intelligence, Resilience and Job Satisfaction were compared across three levels of administrative hierarchy, i.e. Short (less than 10 years of service), Medium (10 to 20 years of service), and Long (more than 20 years of service). Significant difference was found in stress levels across three levels of administrative hierarchy, wherein officers in Short service category exhibited the least amount of stress, while those in Long service category showed the highest amount of stress. Semi-structured interviews were conducted to understand in depth the various factors contributing to the occupational stress in Indian bureaucrats.

Keywords: Occupational Stress, Bureaucracy, EQ, Resilience, Job Satisfaction

Stress has emerged as a rather familiar term in contemporary circumstances. It is so frequently used in common parlance that most people have developed some appreciation about its meaning. The roots of the term itself can, however, be traced back to the Latin word 'Stringere', meaning to tighten. With time, the term stress became popularized to signify hardships or adversities. Work or Occupational stress has been conceptualized as the physiological and emotional responses that occur when workers perceive an imbalance between their work demands and their

\footnotetext{
${ }^{1}$ Research Scholar, Department of Psychology, University of Delhi, India

${ }^{2}$ Department of Psychology, University of Delhi, India

*Responding Author

(C) 2016, R Saroha, N Chadha; licensee IJIP. This is an Open Access Research distributed under the terms of the Creative Commons Attribution License (http://creativecommons.org/licenses/by/2.0), which permits unrestricted use, distribution, and reproduction in any Medium, provided the original work is properly cited.
} 


\section{Indian Bureaucrats across Different Lengths of Service: A Comparative Study}

capability and/or resources to meet these demands. It is important to consider that stress responses have a cognitive origin. Unpleasant reactions to stress occur when the said imbalance is perceived as prominent and the workers believe they are not coping in situations where it is important to them that they cope. Beehr and Newman (1978) have defined occupational stress as “a situation wherein job-related factors interact with a worker to change (i.e., disrupt or enhance) his or her psychological or physiological condition such that the person (i.e., mind-body) is forced to deviate from normal functioning."

While some workplace stress is normal, excessive stress can interfere with an individual's productivity and adversely impact his/her physical and emotional health. Understanding work stress is extremely important in view of the fact that the ability and skill to deal with it can mean the difference between success and failure. Organizations worldwide have awakened to the adverse effects of occupational or work stress.

The consequences of work stress range from employees' individual productivity and the overall organizational profitability, to employees' personal well being. Although the economic downturns created by work stress can prove colossal in today's competitive scenario, yet its impact on employees' well-being should not be underestimated. Closely associated with this well-being are the work attitudes harboured by the employees. Quite importantly, this kind of stress can bring about a significant and undesirable change in employees' work attitudes. Occupational stress has been shown to have strong associations with many adverse organizational outcomes. One of the most consistent findings is that higher levels of job stress are associated with lower levels of job satisfaction (Spector, 1997).

The sources of job stress, as pointed out by Marshall and Cooper (1979) can be understood to exist at both the organizational and non-organizational levels. The organizational stressors are the ones which are inherent in the nature and character of the organizations involved. These can include relationship with boss and colleagues, communication, lack of social support, etc. On the other hand, the non-organizational stressors exist outside the organization but nevertheless serve to produce stress in the employees. These can include factors like family problems, life crises, etc.

A peculiar aspect of work stress is manifested in the difference in its determinants with respect to different types of jobs. One factor might be a major stressor for the employees in one particular job, while the same might not even be considered a stressor at all in another. Different factors contribute to the work stress of employees in different streams and sectors of employment which are essentially rooted in the inherent facets of specific jobs and their requirements, roles and role demands. Therefore, the present study has been conducted taking into consideration the occupational stress experienced by the Indian bureaucrats while attempting to explore the unique stressors offered by this occupation. 


\section{Indian Bureaucrats across Different Lengths of Service: A Comparative Study}

Historically as well as contemporarily, Indian civil services have always been highly important. Indian civil servants have formed the very fabric of public administration of our country. Even during the British colonial rule in India, it was these civil servants who were tasked with administering at the national level as well as the provinces. The contemporary All-India Service forms the frontline of the administrative task force of our country. The unique work settings and changing circumstances have rendered Indian civil services highly stressful. This needed to be empirically investigated in association with other variables which can't be ignored in the bureaucratic context of India.

Occupational stress has been closely associated with factors such as Job Satisfaction, Resilience, and Emotional Intelligence. While assessing the occupational stress of Indian bureaucrats, these variables ought to be taken into consideration. According to Vroom (1964), job satisfaction is “a worker's positive or negative emotional reaction to his/her role at work or in work-related matters". It has also been proposed that job satisfaction stems out of a worker's response to the stimuli provided in the work environment. Schermerhorn, Hunt and Osborn (1994) on similar lines conceptualized job satisfaction as a sense of overall contentment (positive feelings) and discontentment (negative feelings) related to one's job or work.

A very widely accepted research definition of job satisfaction was proposed by Locke (1976), who defined it as “. . . a pleasurable or positive emotional state resulting from the appraisal of one’s job or job experiences” (p. 1304). A close consonance between affect and cognition is inherent in this definition. This means that both affect (feeling) and cognition (thinking) are important in equal measures. When we think about something, we tend to develop feelings about it. On the other hand, if we have feelings about something, it is impossible to not think about it. This inextricable linkage between cognition and affect spills over to our jobs as well and we tend to perceive our job as pleasurable when we have positive affect as well as positive cognition about it. This essence of job satisfaction has been captured very well in Locke’s definition.

However, merely conceptualizing a construct fails to do justice to it. It needs to be considered with antecedent and consequence linkages. Occupational stress, though widely prevalent, gets contained through a number of ways. Resilience proves to be one of these ways. Resilience can be understood as the capacity of an individual to adopt well in the face of adversity, or trauma. Whenever an individual comes across a tragedy, or a threat to physical or psychological wellbeing, or any other significant sources of stress, there can be a damaging impact. However, an individual showing resilience would fare better than others at handling such stressors. Wyman, Sandler, Wolchik, \& Nelson (2000) explored the relevance of resilience in acting as a protection against stress and reported that resilience in fact acts as a protection against stress and as a competence promotion mechanism. 


\section{Indian Bureaucrats across Different Lengths of Service: A Comparative Study}

Another important construct of this study is emotional intelligence. The concept of emotional intelligence has been repeatedly applied to the performance of employees at the workplace. Emotional intelligence is nothing but one's ability to deal with one's own emotions effectively as well as others' emotions for pleasant social relations. An extension of this idea would be to be able to regulate one's emotions at the workplace so as to elicit a better job performance. This is in consonance with the popular belief that in order to have a good performance, one should not let emotions and feelings interfere with work. Proceeding from this vantage point, researchers have expended much effort in assessing the emotional intelligence at workplace and its effects on job performance.

The overall work experience is an outcome of the complex interplay of multiple variables at the same time. In the Indian bureaucratic context, the experience of occupational stress is expected to be influenced by a number of factors. Literature has been reviewed in order to understand the dynamic inter-relationships between these factors. Ahsan, Abdullah, Fie, \& Alam (2009) investigated the relationship between job stress and job satisfaction and found a significant negative relationship between job stress and job satisfaction. Similar results were obtained by Aghdasi, Kiamanesh, \& Ebrahim (2011) who found that occupational stress has a direct negative effect on job satisfaction. They also found that emotional intelligence does not have any direct and indirect effects on occupational stress, which was in disagreement with the results of many other research studies. Chhabra \& Mohanty (2013), for instance, found that there was a negative correlation between Emotional Intelligence and work stress.

Kim, Oh \& Park (2011) studied resilience, occupational stress and satisfaction in nurses. It was found that resilience had a significant difference according to the age and marital status. Resilience was found to have a negative correlation with occupational stress, and had a positive correlation with occupational satisfaction. They concluded that the higher their resilience was the lower their occupational stress and the higher the occupational satisfaction. Shukla \& Nagar (2013) conducted a study to assess the impact of gender and managerial levels on emotional intelligence and job performance of Indian Revenue Service officers. 300 IRS officers from three managerial levels (high, medium, low) were assessed on emotional intelligence and job performance. It was found that female officers manifested relatively higher social skills (component of emotional intelligence) as compared to male officers whereas no difference was found in job performance. Officers of senior managerial level exhibited higher self regulation and social skills and also higher organizational commitment, satisfaction with rewards and incentives as compared to officers belonging to junior and middle managerial level.

\section{METHOD}

\section{Participants}

The participants of the present study are Indian bureaucrats (civil servants) belonging to four civil services namely, the Indian Administrative Service (IAS), the Indian Police Service (IPS), 


\section{Indian Bureaucrats across Different Lengths of Service: A Comparative Study}

the Delhi and Andaman \& Nicobar Islands Civil Service (DANICS) and the Allied services. The total sample size taken for this study is 120, out of whom 76 (63\%) officers are males and 44 (37\%) officers are females. Non-probability convenient sampling has been used. The sample has been categorized on the basis of length of service in order to assess the impact of length of service on the level of occupational stress, and other variables under study. On the basis of length of service, the sample has been categorized into three different categories namely, Short, Medium and Long service. The officers with less than 10 years of service constitute the Short service category. The Medium service category comprises of the officers with 10 to 20 years of service. The officers with more than 20 years of experience are placed into Long service category. Out of the total sample of 120, 45 officers belonged to the Short service category, 37 belonged to Medium service category and the remaining 38 belonged to the Long service category.

\section{Tools Used}

For the purpose of data collection, questionnaires were used. A demographic questionnaire was prepared in order to collect the demographic information. Four different psychological scales were used to measure the four major variables of the study, namely, organizational role stress, job satisfaction, resilience and emotional intelligence. The demographic questionnaire was selfprepared and included questions like name (optional), age, gender, service, batch \& cadre, place of posting, department, designation etc. The information collected from this questionnaire helped in sample categorization.

For measuring the occupational stress, the concept of organizational role stress was used. The tool used was the Organizational Role Stress (ORS) Scale by Udai Pareek (1983). It includes ten dimensions of role stress, each forming a subscale. The total number of items in the scale is 50 . These 50 items are divided into 10 subscales, each consisting of 5 items. These are Inter Role Distance (IRD), Role Stagnation (RS), Role Expectation Conflict (REC), Role Erosion (RE), Role Overload (RO), Role Isolation (RI), Personal Inadequacy (PI), Self Role Distance (SRD), Role Ambiguity (RA), and Resource Inadequacy (RIn).

Job Satisfaction was measured using Brayfield \& Rothe's (1951) Index of Overall Job Satisfaction. It is an 18-item likert type scale with five response categories. Half of the items (9 out of 18) are negatively worded, and hence, reverse scored. The response categories are: "Strongly Agree, Agree, Undecided, Disagree and Strongly Disagree". These are scored as 5, 4, 3 , 2, and 1 , respectively, in the positively worded items. On the other hand, they are scored as 1 , $2,3,4$, and 5 , respectively in the negatively worded items. The overall job satisfaction score is obtained by adding the scores on all items, which ranges from 18 to 90 with high score indicating high job satisfaction. 


\section{Indian Bureaucrats across Different Lengths of Service: A Comparative Study}

For measuring the emotional intelligence of the bureaucrats, the EQ Test by Chadha \& Singh (2006) was used. It has 22 situational items so as to measure emotional responses of the respondents to different situations while requiring them to answer on the basis of how they feel and not what they think. Each item has four alternative courses of action as response choices. These responses vary in the degree of their emotional appropriateness. The responses are scored accordingly (as 5, 10, 15, or 20) on the basis of emotional appropriateness, with the most appropriate receiving the highest scoring (20) and the least appropriate response is scored the least (5). Thus, the total score on the scale ranges from 110 to 440, with high score indicating high emotional intelligence. This scale measures three dimensions of emotional intelligence, namely Emotional Sensitivity, Emotional Maturity and Emotional Competency.

For measuring resilience, the 10-item version Connor-Davidson Resilience Scale (CD-RISC-10) was used. The scale requires the respondents to assess the applicability of each item to them over the past month and then indicate this by selecting one of the five given choices. These response choices are scored by assigning the scores of $0,1,2,3$, and 4 , respectively. All the items are positively worded and hence, there is no reverse scoring. Therefore, the range of possible score on this scale is from 0 to 40 , with higher score indicating higher resilience. This is a global score, and there are no sub-dimensions in this scale.

\section{Procedure}

The participants were selected from all over India through non-probability convenience sampling technique. The respondents were approached. Data was collected through personal meetings as well as through postal and electronic mail. This data was then statistically analyzed. Two hypotheses were formulated for investigation in the present study:

H01: There is a significant difference in the occupational stress levels of the bureaucrats serving at three levels of administrative hierarchy (higher, medium, and lower levels based on the length of service)

H02: There is a significant difference in the EQ, Resilience and Job Satisfaction levels of the bureaucrats serving at three levels of administrative hierarchy (higher, medium, and lower levels based on the length/tenure of service)

Semi-structured interviews were conducted with seven participants to understand in depth the various factors contributing to the occupational stress in Indian bureaucrats.

\section{Data Analysis}

Data were analyzed in multiple phases beginning with the descriptive statistics which included calculation of mean and standard deviation for the scores obtained by the participants on each of the variables. Then on, inferential statistics were used for comparison of means across different lengths of service through Analysis of Variance (ANOVA). The SPSS-16 computer package was used to conduct the statistical analysis and data processing. The qualitative data generated from semi-structured interviews were analyzed using 'Content Analysis'. The data was carefully 
analyzed and systematically classified through the process of coding and broad themes and patterns were identified.

\section{RESULTS}

The mean ORS Total scores as well as scores of ten role stresses obtained by the officers belonging to the three categories based on length of service were compared using the one-way ANOVA The results obtained have been presented in the tables below.

Table 1: Comparison on the basis of Length of Service: ORS

\begin{tabular}{|c|c|c|c|c|c|}
\hline Variable & $\begin{array}{l}\text { Length of } \\
\text { Service }\end{array}$ & $\mathbf{N}$ & Mean & Std. Deviation & F Value \\
\hline \multirow{4}{*}{ IRD } & Short & 45 & 10.62 & 3.682 & \multirow{4}{*}{$9.997 * *$} \\
\hline & Medium & 37 & 14.11 & 4.408 & \\
\hline & Long & 38 & 14.16 & 4.451 & \\
\hline & Total & 120 & 12.82 & 4.468 & \\
\hline \multirow{4}{*}{ RS } & Short & 45 & 11.24 & 2.978 & \multirow{4}{*}{$15.870^{* *}$} \\
\hline & Medium & 37 & 14.59 & 3.586 & \\
\hline & Long & 38 & 15.50 & 4.373 & \\
\hline & Total & 120 & 13.63 & 4.083 & \\
\hline \multirow{4}{*}{ REC } & Short & 45 & 11.96 & 4.079 & \multirow{4}{*}{$6.143^{* *}$} \\
\hline & Medium & 37 & 14.51 & 3.429 & \\
\hline & Long & 38 & 14.42 & 3.803 & \\
\hline & Total & 120 & 13.53 & 3.962 & \\
\hline \multirow{4}{*}{$\mathbf{R E}$} & Short & 45 & 11.76 & 3.491 & \multirow{4}{*}{$6.474^{* *}$} \\
\hline & Medium & 37 & 14.68 & 3.816 & \\
\hline & Long & 38 & 14.18 & 4.632 & \\
\hline & Total & 120 & 13.43 & 4.160 & \\
\hline \multirow{4}{*}{ RO } & Short & 45 & 11.76 & 3.452 & \multirow{4}{*}{$7.864 * *$} \\
\hline & Medium & 37 & 14.68 & 3.621 & \\
\hline & Long & 38 & 14.34 & 4.035 & \\
\hline & Total & 120 & 13.48 & 3.904 & \\
\hline \multirow{4}{*}{ RI } & Short & 45 & 11.13 & 3.533 & \multirow{4}{*}{$7.542 * *$} \\
\hline & Medium & 37 & 14.51 & 4.201 & \\
\hline & Long & 38 & 13.08 & 4.194 & \\
\hline & Total & 120 & 12.79 & 4.173 & \\
\hline \multirow{4}{*}{ PI } & Short & 45 & 11.53 & 3.279 & \multirow{4}{*}{$8.599 * *$} \\
\hline & Medium & 37 & 13.86 & 3.831 & \\
\hline & Long & 38 & 14.84 & 4.188 & \\
\hline & Total & 120 & 13.30 & 3.989 & \\
\hline
\end{tabular}

(c) The International Journal of Indian Psychology, ISSN 2348-5396 (e)| ISSN: 2349-3429 (p) | 101 
Indian Bureaucrats across Different Lengths of Service: A Comparative Study

\begin{tabular}{|c|c|c|c|c|c|}
\hline Variable & $\begin{array}{c}\text { Length of } \\
\text { Service }\end{array}$ & $\mathbf{N}$ & Mean & Std. Deviation & F Value \\
\hline \multirow{4}{*}{ SRD } & Short & 45 & 12.02 & 3.671 & \multirow{4}{*}{$8.289 * *$} \\
\hline & Medium & 37 & 14.27 & 4.194 & \\
\hline & Long & 38 & 15.39 & 3.738 & \\
\hline & Total & 120 & 13.78 & 4.090 & \\
\hline \multirow{4}{*}{ RA } & Short & 45 & 10.78 & 3.483 & \multirow{4}{*}{$7.746^{* *}$} \\
\hline & Medium & 37 & 13.19 & 3.879 & \\
\hline & Long & 38 & 13.89 & 4.105 & \\
\hline & Total & 120 & 12.51 & 4.021 & \\
\hline \multirow{4}{*}{ RIN } & Short & 45 & 10.87 & 3.829 & \multirow{4}{*}{$7.781^{* *}$} \\
\hline & Medium & 37 & 14.00 & 4.478 & \\
\hline & Long & 38 & 13.95 & 4.268 & \\
\hline & Total & 120 & 12.81 & 4.408 & \\
\hline \multirow{4}{*}{ ORS Total } & Short & 45 & 113.67 & 23.623 & \multirow{4}{*}{$16.453^{* *}$} \\
\hline & Medium & 37 & 142.41 & 27.862 & \\
\hline & Long & 38 & 143.76 & 30.410 & \\
\hline & Total & 120 & 132.06 & 30.556 & \\
\hline
\end{tabular}

Emotional intelligence was also compared on the basis of length of service. The mean scores on the three components of EQ as well as EQ Total were compared using One-way Analysis of Variance (ANOVA). The calculated F values are presented in Table 2.

Table 2: Comparison on the basis of Length of Service: EQ

\begin{tabular}{|c|c|c|c|c|c|}
\hline Variable & $\begin{array}{l}\text { Length of } \\
\text { Service }\end{array}$ & $\mathbf{N}$ & Mean & Std. Deviation & F Value \\
\hline \multirow{4}{*}{$\begin{array}{l}\text { Emotional } \\
\text { Sensitivity }\end{array}$} & Short & 45 & 81.11 & 12.518 & \multirow{4}{*}{$3.354^{*}$} \\
\hline & Medium & 37 & 74.05 & 17.112 & \\
\hline & Long & 38 & 73.03 & 17.303 & \\
\hline & Total & 120 & 76.38 & 15.917 & \\
\hline \multirow{4}{*}{ Emotional Maturity } & Short & 45 & 103.89 & 19.653 & \multirow{4}{*}{.447} \\
\hline & Medium & 37 & 100.68 & 19.585 & \\
\hline & Long & 38 & 104.61 & 18.468 & \\
\hline & Total & 120 & 103.13 & 19.175 & \\
\hline \multirow{4}{*}{$\begin{array}{l}\text { Emotional } \\
\text { Competency }\end{array}$} & Short & 45 & 170.44 & 28.838 & \multirow{4}{*}{1.738} \\
\hline & Medium & 37 & 157.30 & 30.993 & \\
\hline & Long & 38 & 165.13 & 35.764 & \\
\hline & Total & 120 & 164.71 & 32.021 & \\
\hline \multirow{4}{*}{ EQ Total } & Short & 45 & 355.44 & 41.284 & \multirow{4}{*}{2.202} \\
\hline & Medium & 37 & 332.03 & 52.420 & \\
\hline & Long & 38 & 342.76 & 58.109 & \\
\hline & Total & 120 & 344.21 & 51.048 & \\
\hline
\end{tabular}

(c) The International Journal of Indian Psychology, ISSN 2348-5396 (e)| ISSN: 2349-3429 (p) | 102 
The comparison of Resilience on the basis of length of service using One-way Analysis of Variance (ANOVA) yielded no significant difference.

Table 3: Comparison on the basis of Length of Service: Resilience

\begin{tabular}{|c|l|l|l|l|l|}
\hline \multicolumn{1}{|c|}{ Variable } & $\begin{array}{c}\text { Length of } \\
\text { Service }\end{array}$ & \multicolumn{1}{|c|}{$\mathbf{N}$} & Mean & Std. Deviation & \multirow{2}{*}{ F Value } \\
\hline \multirow{4}{*}{ Resilience } & Short & 45 & 26.73 & 5.520 & \multirow{3}{*}{.047} \\
\cline { 2 - 5 } & Medium & 37 & 26.97 & 4.850 & \\
\cline { 2 - 5 } & Long & 38 & 27.08 & 5.494 & \\
\cline { 2 - 5 } & Total & 120 & 26.92 & 5.272 & \\
\hline
\end{tabular}

The comparison of Job Satisfaction across three lengths of service using One-way Analysis of Variance (ANOVA) yielded a significant difference between the mean scores of the officers belonging to each of the three categories, as depicted in Table 4 .

Table 4: Comparison on the basis of Length of Service: Job Satisfaction

\begin{tabular}{|c|l|l|l|l|l|}
\hline Variable & $\begin{array}{c}\text { Length of } \\
\text { Service }\end{array}$ & $\mathbf{N}$ & Mean & Std. Deviation & \multirow{2}{*}{ F Value } \\
\hline \multirow{4}{*}{ Job Satisfaction } & Short & 45 & 69.58 & 6.366 & \multirow{3}{*}{$10.798^{* *}$} \\
\cline { 2 - 5 } & Medium & 37 & 61.62 & 9.438 & \\
\cline { 2 - 5 } & Long & 38 & 64.03 & 8.245 & \\
\cline { 2 - 5 } & Total & 120 & 65.37 & 8.643 & \\
\hline
\end{tabular}

$* * p<0.01$

Content Analysis of qualitative data obtained from semi-structured interviews yielded seven themes: Shortage of Workforce/Staff crunch, Excessive Workload, High accountability, Political Pressure, Subordinates' incompetence, and Compromised family life.

\section{DISCUSSION}

The aim of the present study was to compare the bureaucrats on the basis of the length of service which reflects the three levels of administrative hierarchy. Two hypotheses (Hypotheses 1 and 2) were formulated to compare the results on all four variables across three lengths of service. Hypothesis 1 dealt with the comparison of only the ORS scores, while the Hypothesis 2 dealt with the comparison of scores on EQ, Resilience and Job Satisfaction across different lengths of service. The comparison on the basis of length of service was undertaken on the premise that as the officers progress through their careers, their roles and responsibilities become more numerous and more challenging preparing the groundwork for higher occupational stress. One way ANOVA calculated on ORS scores across three levels of administrative hierarchy based on length of service (i.e. Short service: less than 10 years of service; Medium service: 10 to 20 years of service; and Long service: 20 to 30 years of service) showed that each of the calculated $\mathrm{F}$

(C) The International Journal of Indian Psychology, ISSN 2348-5396 (e)| ISSN: 2349-3429 (p) | 103 


\section{Indian Bureaucrats across Different Lengths of Service: A Comparative Study}

values was found to be significant, implying that officers belonging to three hierarchical levels differed significantly from each other on all sub-dimensions of ORS as well as ORS Total scores. Hence, Hypothesis 1 was proved. Organizational Role Stress (ORS) experienced by bureaucrats can be expected to enhance or decline in relation with the gamut of responsibilities they shoulder. Accordingly, the present analysis has revealed that the officers belonging to the Long service category demonstrated the highest level of organizational role stress, followed by the Medium service category while the Short service category exhibiting the least amount of organizational stress. The officers with less than 10 years of service are relatively new in the services. As such the scope of their responsibilities is limited and freshly out of training, enthusiastic, they are able to perform their job well and with full dedication. This implies that their occupational stress is at the minimal. As they progress from Short to Medium service, their participation in policy formulation and implementation increases. The findings arrived at highlighting variation in occupational stress level with the level of administrative hierarchy can be supported by research studies in literature which have yielded similar results. Yasmeen \& Supriya (2010) conducted a research on bureaucrats belonging to the Indian Administrative Service (IAS), Tamil Nadu Cadre. The respondents were compared on the ten role stress dimensions using the Occupational Role Stress (ORS) scale across three levels of service or career stages. The researchers found that the three career stages differed significantly on overall role stress, and the dimensions of role stagnation, role expectation conflict, self-role distance, and role ambiguity. Semi-structures interviews revealed that shortage of workforce, work overload, low competence of junior staff and political pressures are major contributors of bureaucrats' work stress.

Hypothesis 2 stated that there is a significant difference in the EQ, Resilience and Job Satisfaction levels of the bureaucrats serving at three levels of administrative hierarchy. Based on the findings, Hypothesis 2 was partially proved. The comparison of Emotional Intelligence across three administrative hierarchies showed that there was a significant difference only on the Emotional Sensitivity dimension of EQ, whereas no significant difference was found on overall EQ exhibited by them. It is thus safe to contend that in large part, the EQ did not vary with the length of service. These findings can be addressed in the light of certain similar research studies. Rajkhowa (2002) attempted to compare the EQ of IAS officers on the basis of age. It was found that older group of officers exhibited higher EQ as compared to the younger officers, though this difference was not found to be significant. No significant difference was found between mean scores of officers from different lengths of service on Resilience. However, Job Satisfaction when compared on the basis of length of service, a significant difference was found between the mean scores of the officers belonging to each of the three categories made on the basis of length of service. These findings are well-supported by the results from qualitative research. The respondents belonging to Short service revealed that they are quite happy with their jobs. Job satisfaction exhibited by Medium and Long service officers was significantly lower than the Short service officers. It could be reasoned that there are a number of problems and challenges

(C) The International Journal of Indian Psychology, ISSN 2348-5396 (e) | ISSN: 2349-3429 (p) | 104 
faced by the civil servants, especially at the senior and medium level, which results in a decline of job satisfaction. A major problem faced by the civil servants is political interference and manipulation. A number of research studies have validated this. For example, Sekar (2015) observed that the politicians manipulate the officers any which way suiting their needs. He stated that "If the policy is success, the minister takes the credit, if the policy is failure; the minister takes the opportunity to protect himself and blame the officer concerned who executes it...Today not many civil servants would air their disagreement to the minister”. Apart from political pressures, the civil servants are also under pressure from media and public. If they are presented in the negative light by them, it results in the dissatisfaction with job. With the advent of information technology, it is very easy to share information without verifying its veracity. The Right to Information (RTI) Act, 2005 mandates for the ready sharing of information with the public which also puts pressure on the civil servants to be extra careful with their work. As a result of their fear of being misquoted or framed wrongly, officers choose to not take action and restrict their work (Rajkhowa, 2002). Krishna (2010) also cited salary as a factor which has a role to play.

\section{CONCLUSION AND IMPLICATIONS}

The present study has revealed a number of important findings with regard to the complex and challenging nature of the job of Indian bureaucrats. Increasing the strength of workforce, reduction of work overload experienced by Indian bureaucrats, minimizing political interference in bureaucratic functions, recruiting qualified and competent junior staff, a healthy approach of media and public, etc. are some of the suggested ways of mitigating occupational stress of bureaucrats and enhancing their job satisfaction which would ultimately result in a better bureaucratic performance.

\section{Acknowledgments}

The author appreciates all those who participated in the study and helped to facilitate the research process.

\section{Conflict of Interests}

The author declared no conflict of interests.

\section{REFERENCES}

Aghdasi, S., Kiamanesh, A. R., \& Ebrahim, A. N. (2011). Emotional Intelligence and organizational commitment: testing the mediatory role of occupational stress and job satisfaction. Procedia-Social and Behavioral Sciences, 29, 1965-1976.

Ahsan, N., Abdullah, Z., Fie, D. G., \& Alam, S. S. (2009). A study of job stress on job satisfaction among university staff in Malaysia: Empirical study. European Journal of Social Sciences, 8(1), 121-131. 


\section{Indian Bureaucrats across Different Lengths of Service: A Comparative Study}

Beehr, T. A., and Newman, J. E. (1978). Job stress, employee health, and organizational effectiveness: A facet analysis, model, and literature review. Personnel Psychology, 31(4), 665-699.

Brayfield, A. H., \& Rothe, H. F. (1951). An index of job satisfaction. Journal of Applied Psychology, 35(5), 307-311. In Cook, J. D., Hepworth, S. J., Wall, T. D. \& Warr, P.B. (1981). The Experience of Work. A Compendium and Review of 249 Measures and their Use. Academic Press, 2.2, pp. 16-19.

Chadha, N. K. and Singh, D. (2001). “How to Measure your EQ”. In Singh, D. (2006). Emotional Intelligence at Work: A Professional Guide, New Delhi: Response Books. Sage Publications.

Chhabra, B., \& Mohanty, R. P. (2013). Effect of emotional intelligence on work stress-a study of Indian managers. International Journal of Indian Culture and Business Management, 6(3), 300-313.

Connor, K. M., \& Davidson, J. R. (2003). Development of a new resilience scale: The Connor-Davidson resilience scale (CD-RISC). Depression and anxiety, 18(2), 76-82.

Kim, B. N., Oh, H. S., \& Park, Y. S. (2011). A study of nurses' resilience, occupational stress and satisfaction. Korean Journal of Occupational Health Nursing, 20(1), 14-23.

Krishna, A. (2010). Continuity and change: the Indian administrative service 30 years ago and today. Commonwealth \& Comparative Politics, 48(4), 433-444.

Locke, E. A. (1976). The nature and causes of job satisfaction. In M. D. Dunnette (Ed.), Handbook of industrial and organizational psychology (pp. 1297-1349). Chicago: Rand McNally.

Marshall, J., \& Cooper, C. L. (1979). Executives under pressure: A psychological study. London: Macmillan.

Pareek, U. (1983). Manual for Organizational Role Stress Inventory. Ahmedabad: Navin Publications.

Rajkhowa, R. (2002). Emotional Intelligence of IAS Officers. In Singh, D. (2006). Emotional Intelligence at Work a Professional Guide. Sage Publications: New Delhi

Schermerhorn, J. R., Hunt, J. G., \& Osborn, R. N. (1994). Managing organization behavior. New York: John. Willey \& Sons.

Sekar, R (2015). Civil Service is a Major Bridge between Government and the Public. International Journal of Advanced Scientific Research \& Development. 2(3), 209-216

Shukla, R., \& Nagar, D. (2013). Impact of gender and managerial levels on emotional intelligence and job performance of Indian revenue service officers. Indian Journal of Health and Wellbeing, 4(1), 83.

Spector, P. E. (1997). Job satisfaction: Application, assessment, cause, and consequences. Sage Publications, Inc.

Vroom, H. V. (1964). The determination of job satisfaction work and motivation. New York: John Wiley \& Sons, Inc.

(c) The International Journal of Indian Psychology, ISSN 2348-5396 (e)| ISSN: 2349-3429 (p) | 106 


\section{Indian Bureaucrats across Different Lengths of Service: A Comparative Study}

Wyman, P. A., Sandler, I., Wolchik, S., \& Nelson, K. (2000). Resilience as cumulative competence promotion and stress protection: Theory and intervention. In Cicchetti, D., Rappaport, J., Sandler, I., Weissberg, R. P. (Eds), (2000). The promotion of wellness in children and adolescents. , (pp. 133-184). Washington, DC, US: Child Welfare League of America, xxvi, 515 pp.

Yasmeen, H., \& Supriya, M. V. (2010). Role stress: A career stage comparison. International Journal of Public Administration, 33(7), 357-370.

How to cite this article: R Saroha, N Chadha (2016), Indian Bureaucrats across Different Lengths of Service: A Comparative Study, International Journal of Indian Psychology, Volume 3, Issue 4, No. 60, ISSN 2348-5396 (e), ISSN: 2349-3429 (p), DIP: 18.01.087/20160304, ISBN: 978-1-365-26308-8 